\title{
Frequency Tunable Antenna Using a Magneto-Dielectric Material for DVB-H Application
}

\author{
Laure Huitema, Tibault Reveyrand, Jean-Luc Mattei, Eric Arnaud, \\ Cyril Decroze, and Thierry Monediere
}

\author{
Published in \\ IEEE TRANSACTIONS ON ANTENNAS AND PROPAGATION, VOL. 61, NO. 9, \\ September 2013, pp 4456-4466. \\ doi:10.1109/TAP.2013.2269474
}

Copyright C IEEE 2013

Personal use of this material is permitted. However, permission to reprint/republish or redistribute this material for advertising or promotional purposes or for creating new collective works for resale or redistribution to servers or lists, or to reuse any copyrighted component of this work in other works must be obtained from the IEEE.

http://ieeexplore.ieee.org/xpl/articleDetails.jsp?arnumber $=6542642$ 


\title{
Frequency Tunable Antenna Using a Magneto-Dielectric Material for DVB-H Application
}

\author{
Laure Huitema, Tibault Reveyrand, Member, IEEE, Jean-Luc Mattei, Eric Arnaud, Cyril Decroze, and
} Thierry Monediere, Member, IEEE

\begin{abstract}
This paper presents an ultracompact antenna design suited for digital video broadcasting-handheld (DVB-H) reception devices. The DVB-H frequency band is ranging from 470 to $862 \mathrm{MHz}$ and divided in 49 channels of $8 \mathrm{MHz}$. Designed to be integrated in a tablet, it is not only heavily miniaturized $\left(\lambda_{0} / 49 \times \lambda_{0} / 71 \times \lambda_{0} / 160\right.$ at $\left.470 \mathrm{MHz}\right)$, but also able to cover each channel thanks to the use of a magneto-dielectric material. The advantage of using such a material is studied and described in this paper. Moreover, the operating frequency is continuously tuned over the whole DVB-H band by the integration of a varactor diode. This varactor diode has been characterized and modeled to properly cosimulate its behavior within the antenna. Limitations in terms of accepted power by the diode are emphasizing. Finally, the antenna design, including both magneto-dielectric material and varactor diode is integrated in the DVB-H receiver device. Measurement performances are presented and discussed.
\end{abstract}

Index Terms - Digital video broadcasting-handheld (DVB-H), frequency tunable antenna, magneto-dielectric material, miniature antenna, pattern diversity, varactor diode.

\section{INTRODUCTION}

A NTENNA size reduction is restricted by fundamental physical limits [1]-[3], in terms of tradeoff between radiation performances and input impedance bandwidth. Miniaturization of devices leads to the reduction of antenna's dimensions, which becomes one of the most important challenges [4] for antenna designers. This aspect is even more critical when the targeted application is a low frequency standard as the digital video broadcasting-handheld (DVB-H) for which the operating frequency band is ranging from 470 to 862 MHz. Thus, two drawbacks are emerging:

- the antenna needs to cover a very wide input impedance bandwidth of $59 \%$;

Manuscript received November 28, 2012; revised April 15, 2013; accepted June 03, 2013. Date of publication June 18, 2013; date of current version August 30, 2013. This work was supported in part by the French Research Agency Project NAOMI

L. Huitem, T. Reveyrand, E. Arnaud, C. Decroze, and T. Monediere are with the XLIM Laboratory, OSA Department, Faculté des Sciences et Techniques, 87060 Limoges, France (e-mail: laure.huitema@xlim.fr; reveyrand@gmail.com; eric.arnaud@xlim.fr; cyril.decroze@xlim.fr; thierry.monediere@xlim.fr).

J.-L. Mattei is with LabSticc Laboratory, OSA Department, Faculté des Sciences et Techniques, 87060 Limoges, France (e-mail: jean-luc.mattei@univbrest.fr).

Color versions of one or more of the figures in this paper are available online at http://ieeexplore.ieee.org.

Digital Object Identifier 10.1109/TAP.2013.2269474
- the free space wavelength at $470 \mathrm{MHz}$ is about $60 \mathrm{~cm}$, which is very large in comparison with a DVB-H receiver device, e.g., a Smartphone or a tablet.

Many antennas dedicated to DVB-H reception have been investigated in [5]-[10] and some are working on the whole DVB-H band [5]-[7]. In 2012, Yonghun Cheon presented a dual band planar inverted $\mathrm{F}$ antenna (PIFA), covering the whole DVB-H band and having $70 \mathrm{~mm} \times 30 \mathrm{~mm}$ for overall dimensions, i.e., $\lambda_{0} / 9 \times \lambda_{0} / 21$ at $470 \mathrm{MHz}$ [6]. A total efficiency of $33 \%$ is obtained in the worst case. Another article [7] presents a DVB-H antenna with best performances (total efficiency greater than $70 \%$ ) which possesses dimensions of $\lambda_{0} / 7 \times \lambda_{0} / 13 \times \lambda_{0} / 28$ at $470 \mathrm{MHz}$. In spite of its electrical small sizes, this antenna is too big to be integrated in a DVB-H handheld receiver. Thus, in most cases, wireless device integration remains an important issue for whole-band covered DVB-H antennas. To overcome the DVB-H ultra-wide input impedance bandwidth, some antenna devices integrate active components as presented by M. Berg in [8] or a matching circuit [9]-[11] in order to cover, at least, one user channel of $8 \mathrm{MHz}$. These antennas present low instantaneous impedance bandwidths, thus small sizes and also low total efficiency, mainly induced by impedance matching circuit or active component losses. However, DVB-H specifications require low maximum realized gains, i.e., $-10 \mathrm{dBi}$ at $470 \mathrm{MHz}$ to $-5 \mathrm{dBi}$ at $862 \mathrm{MHz}$ [12].

To cover a wide impedance bandwidth while maintaining very small antennas size, the use of magneto-dielectric materials has been reported in many papers [13]-[19]. According to [13]-[16], magneto-dielectric substrates can permit to overcome the input impedance bandwidth limitation for small antennas compared to dielectric ones. Hansen and Burke [16] have expressed the zero-order impedance bandwidth of a patch antenna printed on a t-thick magneto-dielectric material by the following equation:

$$
B W=\frac{96 \sqrt{\frac{\mu}{\varepsilon}} \cdot \frac{t}{\lambda_{0}}}{\sqrt{2}(4+17 \sqrt{\varepsilon \cdot \mu})} .
$$

Thus, compared to high dielectric permittivity, high permeability materials allow to reduce the size of a patch antenna without decreasing its relative impedance bandwidth. In [17], Niamien et al. investigates magneto-dielectric materials losses and provides expressions of antenna impedance bandwidth and efficiency according to both dielectric and magnetic losses for 
a patch antenna. They showed that both the radiation efficiency and the impedance bandwidth increase with the permeability.

This paper will focus on the miniaturization of a 3-D-shaped full band DVB-H antenna with a high level of integration, for diversity operations. This goal will be achieved through the use of both magneto-dielectric materials and active components. In Section II, the interest of using magneto-dielectric materials on the proposed antenna will be presented through an extensive investigation. Within the framework of these studies, a first prototype measurement will prove the advantage of using such a material for antenna designer's point of view.

Even if the use of magneto-dielectric materials offers great advantages in terms of miniaturization and input impedance bandwidth enhancement, the full DVB-H bandwidth cannot be entirely covered by such a technique. For these reasons, the integration of a varactor diode to tune the operating frequency of the proposed antenna will be investigated in Section III. Firstly, both its position and its characteristics (capacitance value, quality factor, etc.) will be studied in order to tune the antenna all over the DVB-H frequency band. This work will complete the lack of information related to most of varactor diode datasheets. Indeed, they only provide characteristics at low frequencies and do not give enough parameters for antenna application point of view, such as capacitance values, serial resistance and accepted power at $\mathrm{RF}$ frequencies. The chosen varactor has been characterized according to antenna designer criteria and its electromagnetic model has been deduced. This study will also exhibit power handling capability of the varactor diode.

Finally, Section IV will present the final antenna design using both magneto-dielectric material and the characterized varactor diode. The manufactured prototype is integrated in a DVB-H tablet and measured in an anechoic chamber. The small antenna size allows integrating two antennas in the device and therefore applying space diversity. In this framework, diversity performances are evaluated in a reverberation chamber.

\section{Magneto-Dielectric Materials For AntenNa APPLICATIONS}

The currently commercialized magneto-dielectric materials, based on fully sintered ferrite ceramics, show low ferromagnetic resonance (FMR), and high magnetic losses $\left(\tan \delta_{\mu}\right)$ which limit their use below 350-400 MHz. To overcome limits of fully sintered ferrite, porous ceramic have been studied for antenna systems [20].

As mentioned in Section I, the most common antenna using magneto-dielectric materials are patch antennas. The purpose of this part is to prove that in the case of a 3-D inverted $\mathrm{F}$ antenna (IFA), using such kind of materials has same benefits than the ones presented by the literature [13]-[19]. This study is presented in three points:

- an attractive design of a 3D IFA has been firstly investigated;

- three antenna designs: the same antenna design has been studied without material, with a dielectric material and with a magneto-dielectric material, which has the same refractive index;

- a prototype has been manufactured and measured to corroborate the simulations.

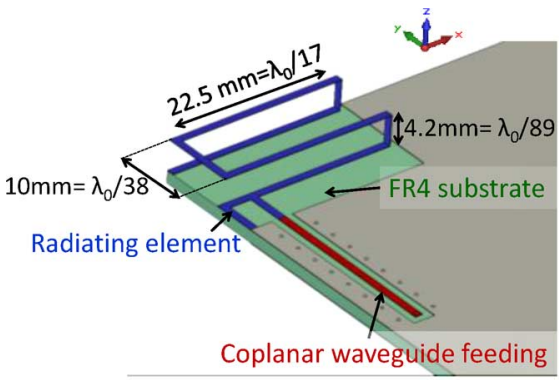

(a)

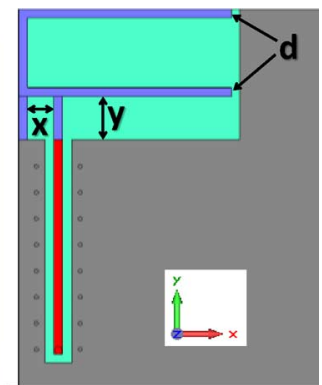

(b)
Fig. 1. 3-D Inverted F Antenna design (a). Antenna top view (b).

\section{A. 3-D Inverted F Antenna Design}

To be integrated in a mobile handheld device, the antenna allocated volume has to be very compact. A good tradeoff between small sizes and the impedance bandwidth is to choose a structure based on the IFA design. Indeed, the radiating monopole of this kind of structure can be folded to become more compact. In this step of the study, the aimed frequency band is the up of the DVB-H band going till $862 \mathrm{MHz}$. The antenna design, presented in the Fig. 1, is a folded metallic ribbon. The ribbon length, and also the gap distances illustrated on Fig. 1 (i.e., $x, y$ and $d$ ) are optimised to match the antenna around $862 \mathrm{MHz}$.

The antenna design is ruled according to the following steps:

- the first horizontal section of the ribbon involves a capacitive effect, which can be compensated by a shorting line;

- the shorting line involves a parallel resonance allowing to set the input impedance without the need of a matching circuit;

$-x$ and $y$ lengths adjust the parallel resonance: the best way is to have the zero of the input impedance imaginary part corresponding to the $50 \Omega$ of the real one;

- the $d$ length between the metallic ribbon and the ground plane also involves a capacitive effect allowing decreasing the resonant frequency.

However, it should be noted that the resonance frequency is paramount governed by the ribbon global length, which could be compared to a quarter wavelength monopole.

This structure presents quietly small dimensions and its shape is interesting with the aim of miniaturizing by loading it with different kinds of materials.

As far as it will be integrated in a tablet, the antenna is studied on a $230 \mathrm{~mm} \times 130 \mathrm{~mm}$ ground plane and incorporated in its corner. The radiating element is fed by a $50 \Omega$ coplanar waveguide printed on a FR4 substrate $\left(\varepsilon_{\mathrm{r}}=4.9\right)$.

\section{B. Three Antenna Designs}

In this subsection, the previous folded monopole is loaded by two materials: a high permittivity material $\left(\varepsilon_{\text {dielectric }}^{\prime}=17\right)$ and a magneto-dielectric material $\left(\varepsilon_{\text {magneto }}^{\prime}=3.5, \mu_{\text {magneto }}^{\prime}=5.5\right)$ as depicted on Fig. 2.

The dielectric permittivity $\varepsilon_{\text {dielectric }}^{\prime}$ is selected in order to ensure a similar miniaturization factor as $\varepsilon_{\text {magneto }}^{\prime}, \mu_{\text {magneto }}^{\prime}$, corresponding to a same refractive index. Thus, except for the volume, which is reduced by a ratio of 1.5 , the antenna design is the same as the reference one (without substrate). The 


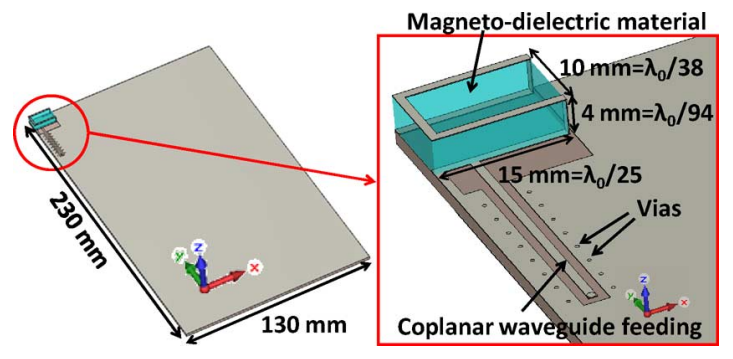

Fig. 2. 3-D Inverted F Antenna loaded by a magneto-dielectric material.

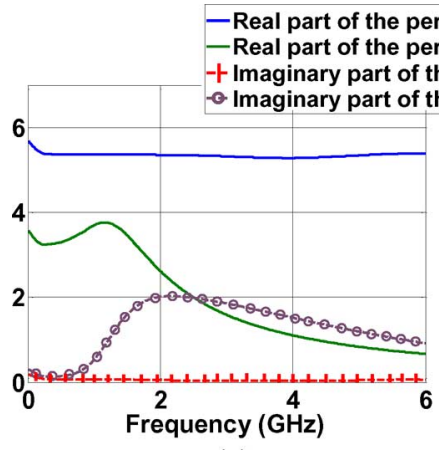

(a)

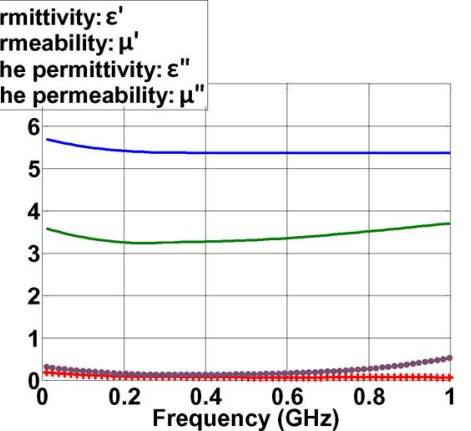

(b)
Fig. 3. Magneto-dielectric measured characteristics.

$\varepsilon_{\text {magneto }}^{\prime}, \mu_{\text {magneto }}^{\prime}$ values are these from a new type of magneto-dielectric material: a Ni-Zn ferrite ceramic with nanosized grains composed by $\mathrm{Ni}_{0,5} \mathrm{Zn}_{0,3} \mathrm{Co}_{0,2} \mathrm{Fe}_{2} \mathrm{O}_{4}$. Ferrite nanoparticles were prepared by a coprecipitation method, and then submitted to appropriate thermal treatments and shaping by uniaxial pressing. More detailed on the material elaboration are available in [20]. The sample parameters $\varepsilon$ (complex permittivity $\varepsilon^{\prime}$-j $\varepsilon^{\prime \prime}$ ) and $\mu$ (complex permeability $\left.\mu^{\prime}-j \mu^{\prime \prime}\right)$ were measured using the transmission/reflection method based on the algorithms of Nicolson, Ross, and Weir [21]. The method is based on the measurements of the scattering parameters of a toroidal sample placed into a coaxial line. Error analysis indicated uncertainties less than 5\% for the data. A Hewlett Packard HP 8753ES network analyzer setup was used to conduct the measurements over the frequency range going from $100 \mathrm{MHz}$ up to $6 \mathrm{GHz}$. The typical dimensions of the toroid are those of APC7 standard (inner diameter $=3.04 \mathrm{~mm}$, outer diameter $=7 \mathrm{~mm}$, length $=2-4 \mathrm{~mm}$ ). All samples were machined in order to avoid the presence of air gaps between the sample and the line walls. The relevant feature for the antenna design is the material electromagnetic characteristics (complex permittivity and complex permeability) presented Fig. 3. As the DVB-H band is aimed in this paper, the area of interest is presented Fig. 3(b).

Unusually for magneto-dielectric materials, these features show that this material can be used up to $1 \mathrm{GHz}$. As defined in [17], both magneto-dielectric and dielectric losses increase the impedance bandwidth. Thus, to carefully compare and provide relevant results relating to the use of a magneto-dielectric material rather than a dielectric one, materials are in a first time considered without any loss. Therefore, antennas reflection coefficient results presented Fig. 4 are for lossless materials.

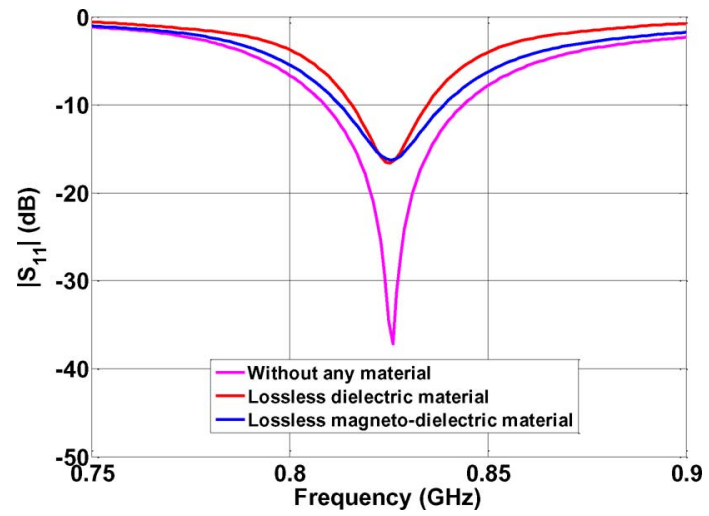

Fig. 4. Reflection coefficients for the three cases.

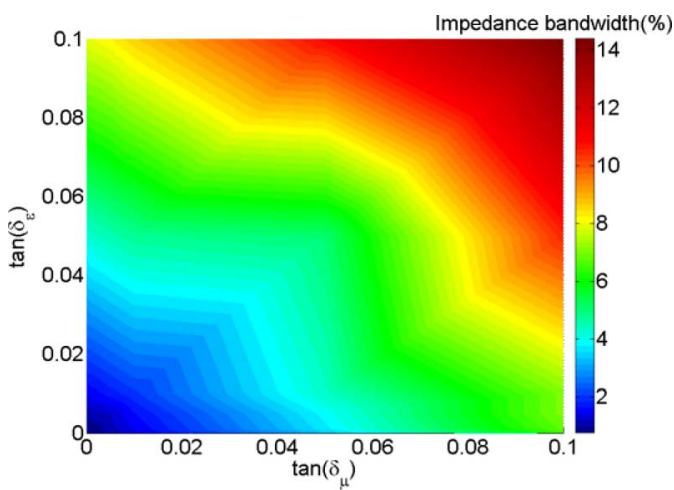

(a)

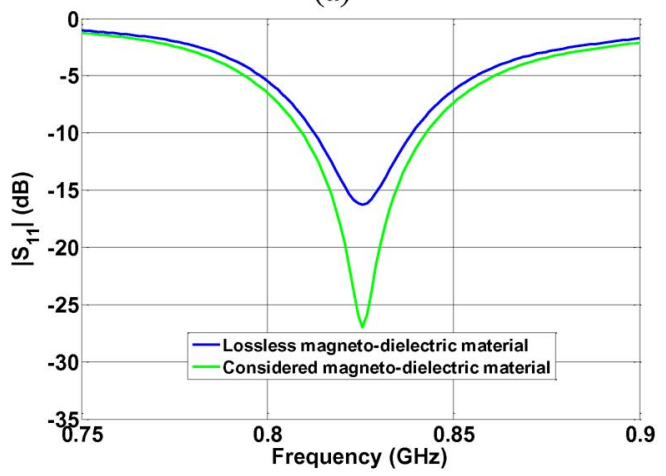

(b)

Fig. 5. Losses effect on the impedance bandwidth (a) and comparison of reflection coefficients for lossless and manufactured magneto-dielectric materials (b).

$\left|\mathrm{S}_{11}\right|$ parameters exhibit $4.2 \%, 3.5 \%$, and $2.29 \%$ impedance bandwidths respectively without any material, for magneto-dielectric and dielectric materials. It should be noted that the design without material presents a larger impedance bandwidth than the two others. However, its volume is far bigger since its dimensions equal $\lambda_{0} / 17 \times \lambda_{0} / 38 \times \lambda_{0} / 89$ at $825 \mathrm{MHz}$ when they equal $\lambda_{0} / 25 \times \lambda_{0} / 38 \times \lambda_{0} / 94$ at $825 \mathrm{MHz}$ for both other cases. The comparison between the dielectric and magneto-dielectric materials shows that using the latter in our antenna design allows increasing its impedance bandwidth.

As lossless materials do not represent the reality, losses are now investigating. In this purpose, losses are injected in the simulation and the Fig. 5 provides the impedance bandwidth according to the material losses. As expected, the impedance bandwidth increases according to both magnetic and dielectric losses. This figure also 
TABLE I

Antenna Performances For Four ReleVant CASEs

\begin{tabular}{|c|c|c|c|c|}
\hline & $\begin{array}{c}\text { Without any } \\
\text { material }\end{array}$ & $\begin{array}{l}\text { Lossless } \\
\text { dielectric }\end{array}$ & $\begin{array}{l}\text { Lossless } \\
\text { magneto- } \\
\text { dielectric }\end{array}$ & $\begin{array}{c}\text { Considered } \\
\text { magneto- } \\
\text { dielectric }\end{array}$ \\
\hline $\begin{array}{l}\text { Matching } \\
\text { frequency }\end{array}$ & $827 \mathrm{MHz}$ & $827 \mathrm{MHz}$ & $827 \mathrm{MHz}$ & $827 \mathrm{MHz}$ \\
\hline \begin{tabular}{|c} 
Input \\
impedance \\
bandwidth \\
$(\mathrm{S} 11<-10 \mathrm{~dB})$ \\
\end{tabular} & $10 \%$ & $4.12 \%$ & $5.93 \%$ & $7.14 \%$ \\
\hline $\begin{array}{c}\text { Total } \\
\text { efficiency }\end{array}$ & $98 \%$ & $98 \%$ & $98 \%$ & $76 \%$ \\
\hline \begin{tabular}{|c|} 
Maximum \\
realized gain
\end{tabular} & $3.2 \mathrm{~dB}$ & $3.2 \mathrm{~dB}$ & $3.2 \mathrm{~dB}$ & $2.3 \mathrm{~dB}$ \\
\hline
\end{tabular}

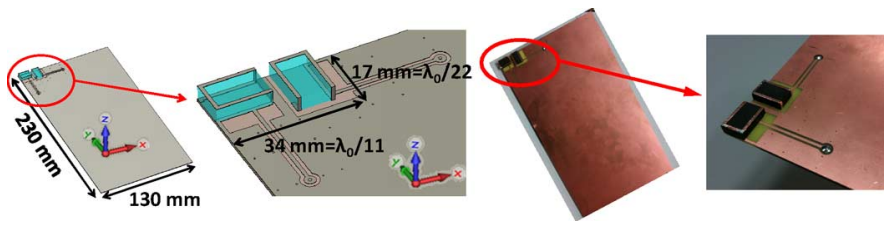

Fig. 6. Final design and manufactured prototype [22].

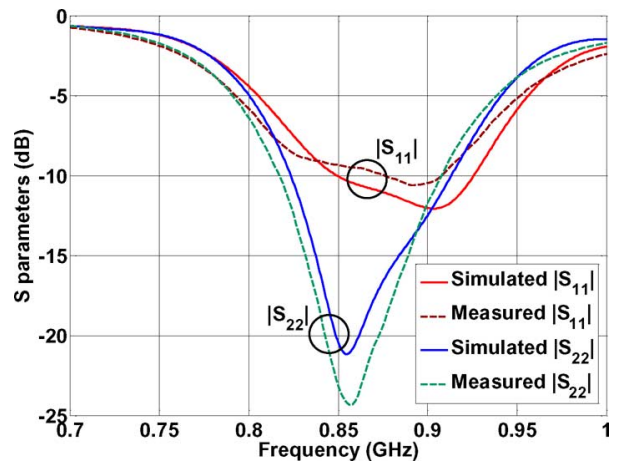

Fig. 7. Measured (dashed lines) and simulated (solid lines) S parameters.

plots the $\left|\mathrm{S}_{11}\right|$ parameter for material properties presented Fig. 3 . The comparison with the lossless case confirms the usefulness of the previous study without any loss.

Thus, the higher the losses are, the larger the input impedance bandwidth is. That involves a decreasing of the total efficiency of the antenna as well. Table I sums up all relevant results for our compact antenna application.

\section{Manufactured Prototype}

In the framework of this study, a first antenna prototype has been manufactured to corroborate simulated performances. It has been presented in [22], [23] and exhibits two radiating elements in the aim of having a reconfigurable radiation pattern (see Fig. 6).

Fig. 7 illustrates the comparison between measured and simulated $\left|\mathrm{S}_{11}\right|$ and $\left|\mathrm{S}_{22}\right|$ parameters. It plots the comparison between simulations and measurement for both $\left|\mathrm{S}_{11}\right|$ and $\left|\mathrm{S}_{22}\right|$ parameters.

Simulated performances are in good agreement with the measured ones. Antenna design and prototype corroborate previous

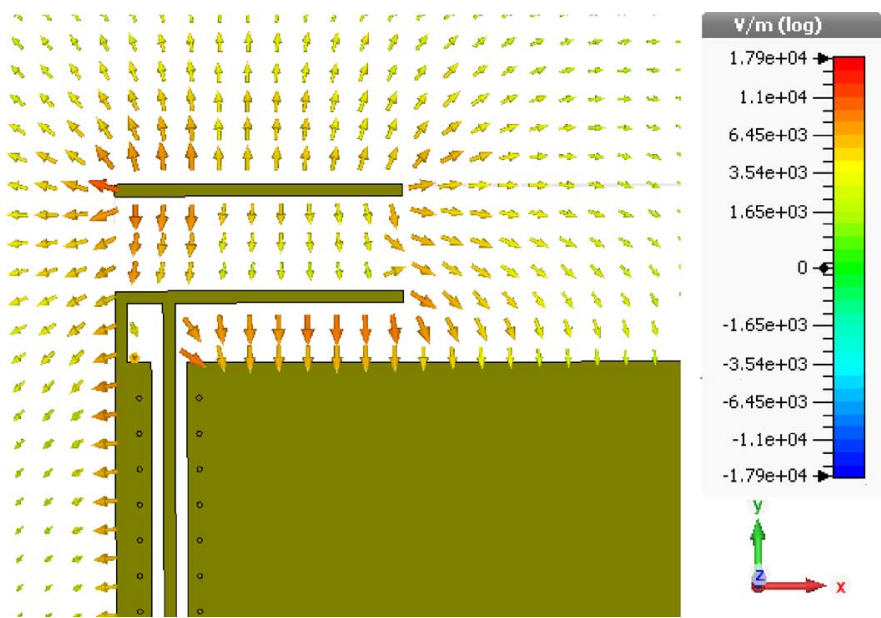

Fig. 8. $\mathrm{E}_{\mathrm{tot}}$ field on the radiating element.

simulations and thus validate that using a magneto-dielectric material allows enhancing the input impedance bandwidth.

Now, basing on the same antenna design, the idea is to integrate a varactor diode to tune the impedance matching all over the DVB-H band.

\section{INTEGRATION OF A VARACTOR DIODE}

The first subsection will investigate the place where the varactor can be integrated. Following the presentation of the varactor diode manufacturer's datasheet, a complete characterization meeting antenna designer's criteria will be explained. That will lead to the determination of the varactor diode $\mathrm{S}$ parameters. With the knowledge of the latter, two methods will be explained and described to reach an accurate antenna simulation and realization:

- the electromagnetic equivalent circuit of the varactor diode can be deduced from the S parameters thanks to Agilent ADS;

- the S parameters of the varactor diode can be directly injected in the electromagnetic simulator CST Microwave Studio and the antenna performances deduced thanks to a cosimulation.

This subsection will also investigate the power handling capability of the varactor diode. The last subsection will treat an example to compare the two methods investigated with the manufacturer's datasheet and also the power issue.

\section{A. The Varactor Diode Placement}

The varactor diode is a tunable capacitor which loads the antenna in order to artificially increase its electrical length. To be the most efficient, it must be placed where the electrical field is maximum. For Inverted F Antennas and thus for the design considered in this paper, the maximum is at the end of the radiating element (see Fig. 8).

To be integrated at this place and joined the ground plane at the same time, the varactor diode can be put under the FR4 substrate as shown Fig. 9.

Another point concerns the capacitance value. It impacts on both the electrical length of the radiating element and the 


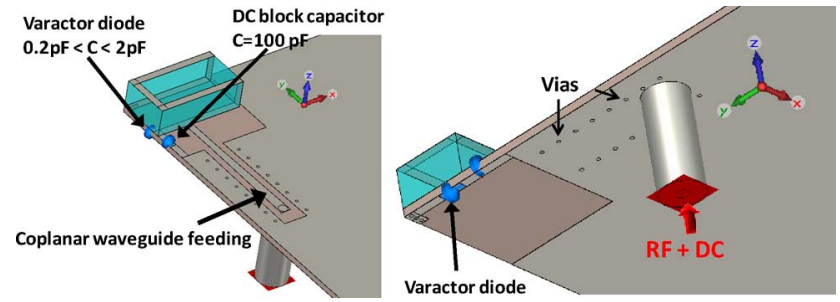

Fig. 9. Design integrating both magneto-dielectric material and a varactor diode.

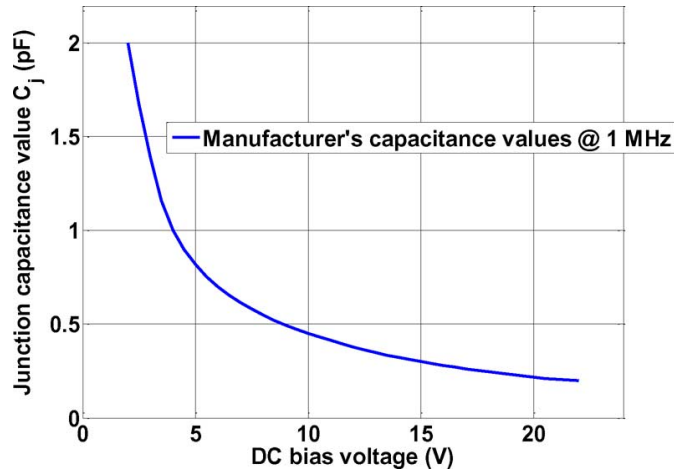

Fig. 10. Manufacturer's capacitance value (extracted at $1 \mathrm{MHz}$ ) versus the DC bias voltage.

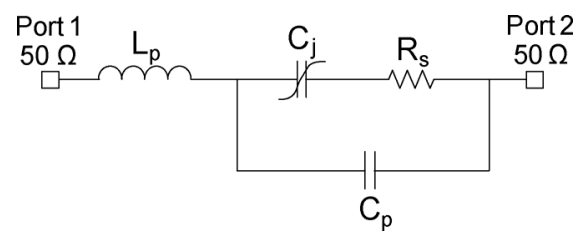

Fig. 11. Varactor diode model.

radiated Q-factor. Indeed, the lower its value is, the upper the $\mathrm{Q}$-factor is. Thus, for high capacitance values, the radiated Q-factor becomes too low and it becomes difficult to match the antenna. Moreover, the capacitance increases the electrical length and therefore also the global size of the antenna. Finally, with a $0.2 \mathrm{pF}-2 \mathrm{pF}$ capacitance values range, the final design depicted Fig. 9, can be tuned all over the DVB-H band. Material dimensions are $11 \mathrm{~mm} \times 7 \mathrm{~mm} \times 3.5 \mathrm{~mm}$, i.e., $\lambda_{0} / 49 \times \lambda_{0} / 91 \times \lambda_{0} / 160$ at $470 \mathrm{MHz}$ and the dedicated area for the antenna structure is about $13.5 \mathrm{~mm} \times 12 \mathrm{~mm} \times 4.3 \mathrm{~mm}$, i.e., $\lambda_{0} / 47 \times \lambda_{0} / 53 \times \lambda_{0} / 148$ at $470 \mathrm{MHz}$.

\section{B. Varactor Diode Datasheet}

The chosen GaAs hyperabrupt varactor diode MGV125-22 (Aeroflex Metelics) [24] has a capacity range between $0.2 \mathrm{pF}$ and $2 \mathrm{pF}$ for 0 to 22 Volts tuning voltage as shown Fig. 10.

However, these values are given as a rough line and the datasheet does not give enough parameters for high frequencies antenna application's point of view. Indeed, the values for junction capacitance $C_{j}$ (Figs. 10 and 11) and the quality factor $Q$ are supplied by the manufacturer and are almost always specified at a low frequency. The Fig. 11 shows the widely used varactor diode model with $L_{p}$ and $C_{p}$ the values of the package inductance and capacitance.

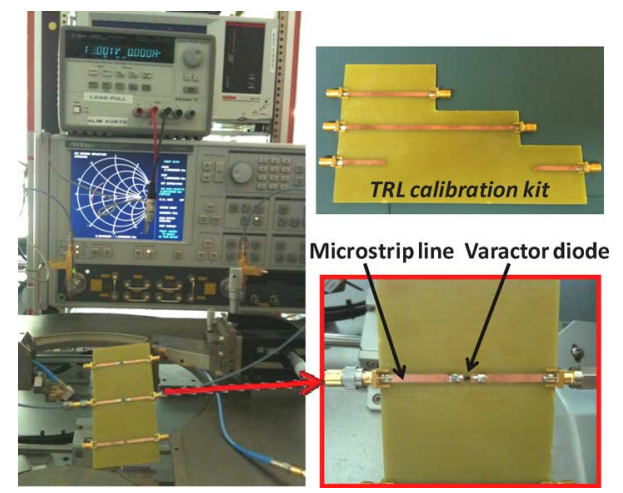

Fig. 12. Characterization of the varactor diode.

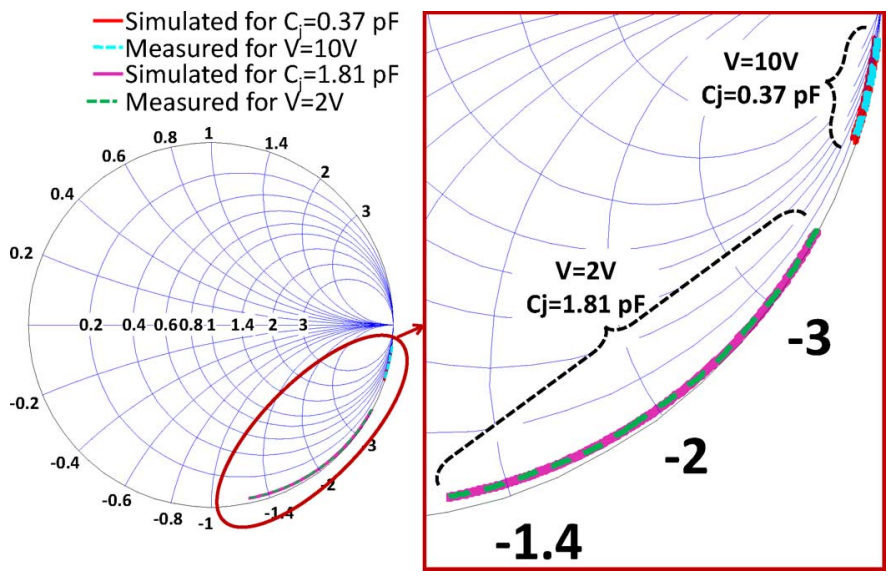

Fig. 13. Comparison between the electromagnetic model and the measurement on $\mathrm{S}_{11}$ parameter on the $[400 \mathrm{MHz}-1 \mathrm{GHz}]$ frequency band.

In the MGV125-22 case, junction capacitance values are specified at $1 \mathrm{MHz}$ and the $Q$ factor equals 3000 at $50 \mathrm{MHz}$ for a DC bias voltage of -4 Volts. $Q$ is defined by $Q=1 / \omega C j R s$. This formula can be used to calculate the series resistance $R s$ of the varactor model at the measured frequency, its value is assumed to be constant with reverse voltage. Thus, at $50 \mathrm{MHz}$ $R s=1.06 \Omega$. It is important to note that $R s$ impacts directly the antenna total efficiency. A too high value (from $3 \Omega$ ) is basically penalizing for antenna performances. This enhances the need to assess its value at microwave frequencies. For this purpose, the hyperabrupt varactor diode is characterized close to operating conditions.

\section{Varactor Diode Characterization}

1) 1st Method: Electromagnetic Model: The varactor diode is soldered on a $50 \Omega$ impedance microstrip line as shown Fig. 12. A dedicated TRL (Through-Reflect-Line) calibration kit is manufactured (see Fig. 12) in order to de-embed both connectors and lines. Thus $\mathrm{S}$ parameters of the single varactor diode can be deduced.

Considering the varactor diode model previously presented in Fig. 11, $C_{j}, L_{p}, C_{p}$, and $R_{\mathrm{s}}$ values can be deduced for each voltage and for a constant injected power of $-10 \mathrm{dBm}$. Therefore, model component values are adjusted (see Fig. 13) in order their $\mathrm{S}$ parameters to correspond with the measured ones. The Fig. 13 shows the comparison between S parameters 


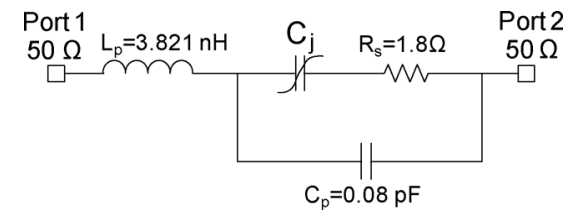

Fig. 14. Electromagnetic model.

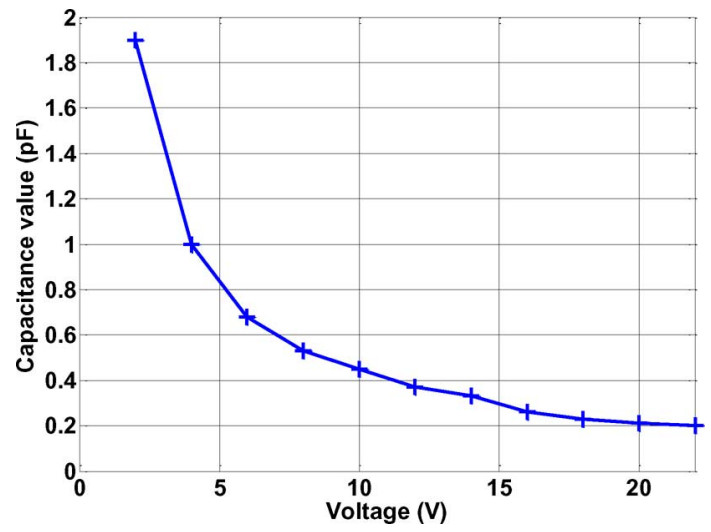

Fig. 15. Capacitance values versus the DC bias voltage.

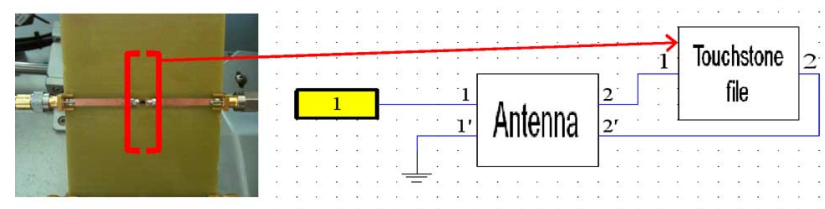

Fig. 16. Co-simulation of the antenna including measured $\mathrm{S}$ parameters of the diode.

of the determined electromagnetic model (Agilent ADS) and the measured ones (see Fig. 12) for 2 Volts and 10 Volts DC bias voltages.

These results are given as an example and the same work has been done for varactor reverse bias voltages varying from $2 \mathrm{~V}$ to $22 \mathrm{~V}$ with a $2 \mathrm{~V}$ step. As expected, the corresponding electromagnetic model presents constant values according to the DC bias voltage (Fig. 14): $\mathrm{L}_{p}=3.821 \mathrm{nH}, \mathrm{C}_{p}=0.08 \mathrm{pF}$, and $\mathrm{R}_{\mathrm{s}}=1.8 \Omega$.

The $\mathrm{C}_{j}$ value presented in Fig. 15 decreases as a function of DC bias voltage value.

2) 2nd Method: CoSimulation: Another way is to directly insert the $\mathrm{S}$ parameters touchstone file of the varactor diode in the antenna electromagnetic simulation as illustrated in Fig. 16.

Thanks to the previous TRL calibration, only the varactor diode S parameters are inserted in the simulator. By this way, both antenna and varactor diode are combined and the S parameters of the global device can be directly simulated. An example (presented paragraph Section III-D) will confirm that the two previous methods exhibit similar antenna performances.

3) Power Characterization: Fig. 17 provides some information regarding the accepted power by the varactor diode: high injected power involves some varactor diode distortions.

This figure presents $S$ parameters of the diode for only three values of injected power: $-10 \mathrm{dBm}, 0 \mathrm{dBm}$ and $10 \mathrm{dBm}$. The nonlinear distortion of the diode has been studied. It reveals

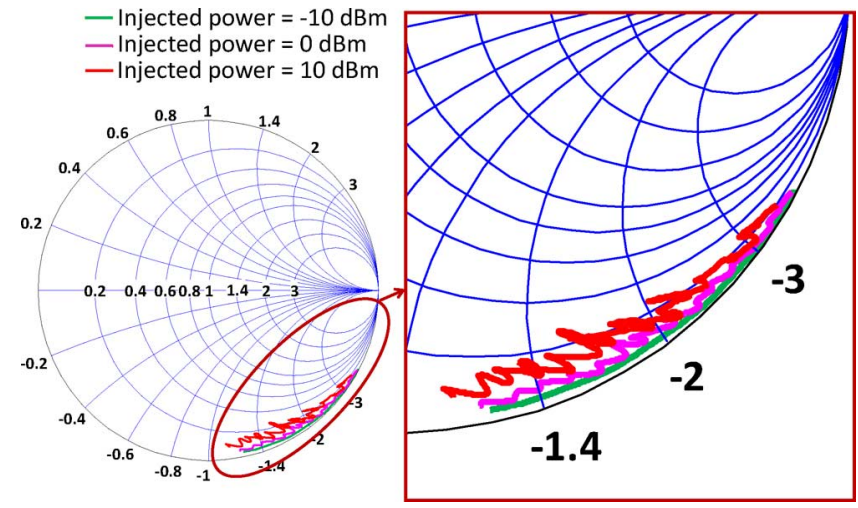

Fig. 17. Measured S parameters according to the injected power.

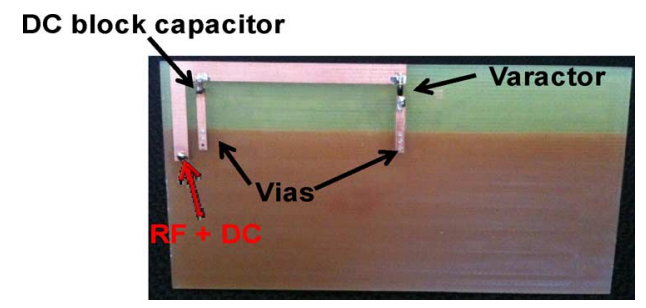

Fig. 18. Basic IFA prototype [25].

that the varactor diode model well fits measurements for an injected $\mathrm{RF}$ power lower than $-5 \mathrm{dBm}$. Beyond this injected power (see for $0 \mathrm{dBm}$ ), no varactor model can fit the measurement. Regarding antenna's parameters, the following example will show that a large RF power (upper than $-5 \mathrm{dBm}$ ) involves a mismatched antenna. As far as the DVB-H application, the system is only working in receiving mode, the diode distortion will never appear and the linear electromagnetic model can be used and integrated in the electromagnetic simulator. Indeed, for receiver devices, the antenna accepted power is far lower than $-5 \mathrm{dBm}$.

\section{Example of a Basic Antenna}

This subsection investigates an example to show the interest of the previous varactor diode characterization. This was briefly presented in [25], it is completed here by adding the first method (electromagnetic model) and the power characterization. A basic IFA prototype loaded by the same varactor diode (see Fig. 18) has been manufactured.

It has been measured for a $-10 \mathrm{dBm}$ RF power and its performances compared with three simulations: with both presented methods and with the varactor diode's datasheet (Fig. 19). $\left|S_{11}\right|$ parameters show that both investigated methods and measurement present a good agreement. Moreover, they are different from $\left|\mathrm{S}_{11}\right|$ parameters determined with the varactor diode datasheet. That underlines the relevance of the varactor diode characterization. Regarding the antenna total efficiency, it equals $50 \%$ in the real case whereas it reaches $60 \%$ when the varactor datasheet is used in electromagnetic simulations.

Power characterization is illustrated on Fig. 20. This figure reminds the measured $\left|S_{11}\right|$ parameter for a power of $-10 \mathrm{dBm}$. For a $10 \mathrm{dBm}$ injected power, the measured $\left|\mathrm{S}_{11}\right|$ parameter is compared with the simulated one with the second method. 


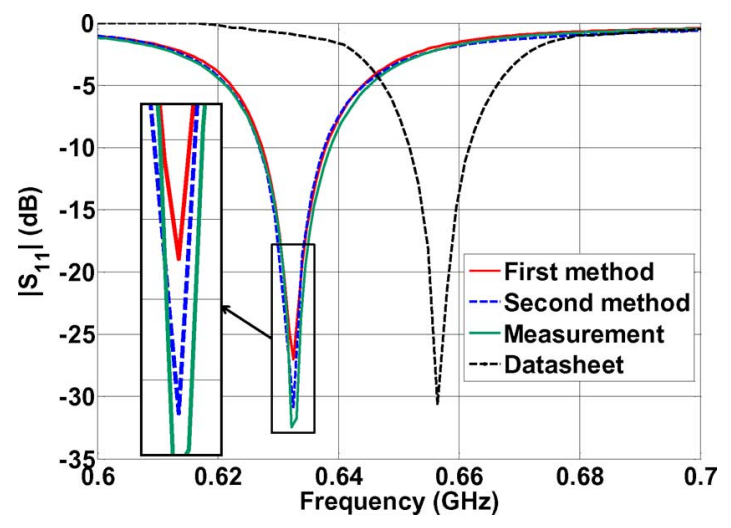

Fig. 19. $\left|\mathrm{S}_{11}\right|$ parameters for different cases.

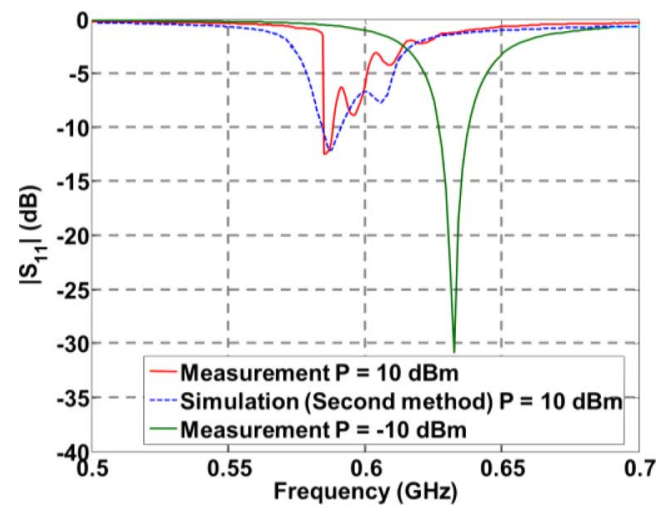

Fig. 20. $\left|\mathrm{S}_{11}\right|$ parameters according to the injected power.

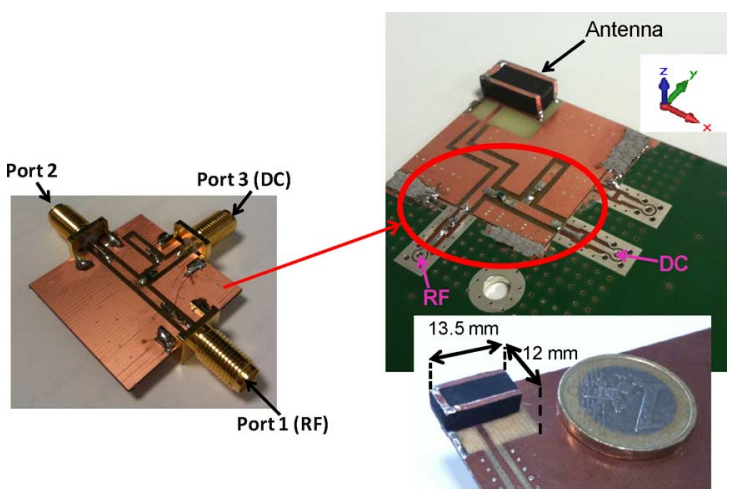

Fig. 21. DC bias Tee with SMD components and its integration upstream from the antenna.

There is a good agreement between the measurement and the simulation. This figure shows that the nonlinearity of the varactor diode disturbs the $\left|\mathrm{S}_{11}\right|$ parameter of the antenna. Thus, this kind of varactor diode has to be used only for reception devices.

Therefore, this section has presented how to integrate and characterize a varactor diode. It reveals the importance of the diode characterization in a design flow dedicated to antenna structure.

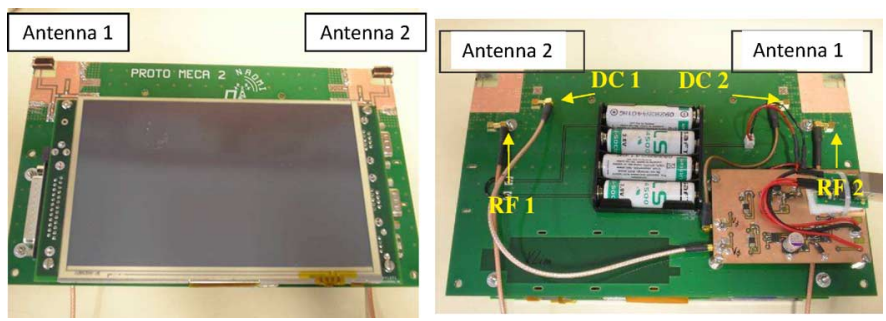

Fig. 22. Integration of two antennas in the tablet dedicated to the DVB-H reception.

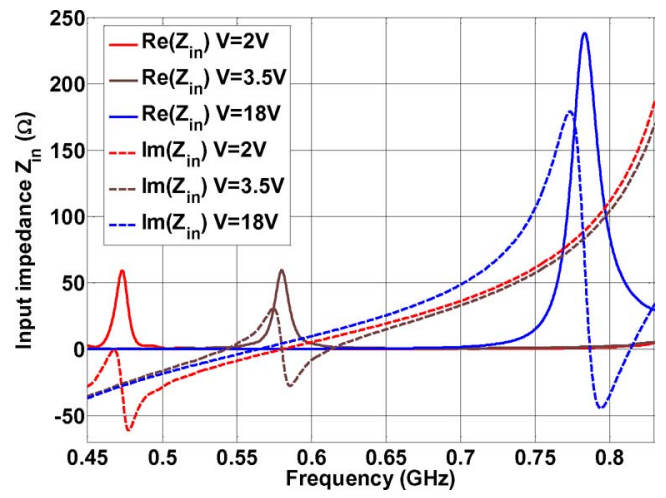

Fig. 23. Measured input impedances versus frequency for several DC bias voltages.

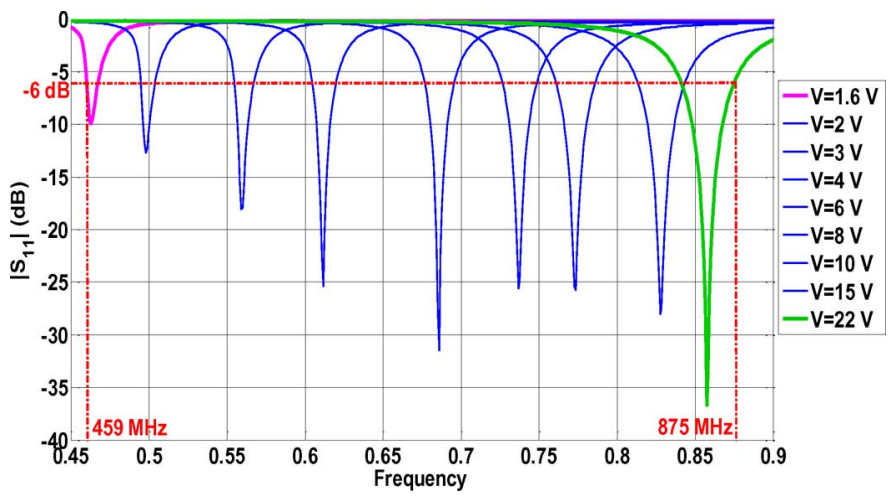

Fig. 24. Measured reflection coefficients for several DC bias voltages.

\section{Antenna Performances}

\section{A. Measured and Simulated Performances of the Antenna}

A prototype of the tunable antenna has been realized (see Fig. 21) and measured. For the diode polarization, a DC bias Tee is optimized with SMD components and measured on the DVB-H band (see Fig. 21). After being validated, it is integrated upstream from the antenna structure as shown Fig. 21.

In order to improve the quality and the reliability of wireless links, the final mobile device is integrating two antennas (see Fig. 22) for diversity operations.

Figs. 23 and 24 present, respectively, the variation of the input impedances and $\left|\mathrm{S}_{11}\right|$ parameters of the antenna versus frequency for different values of the varactor diode bias voltages.

There is a good agreement between simulation and measurement. Indeed, the antenna working band is continuously tuned 


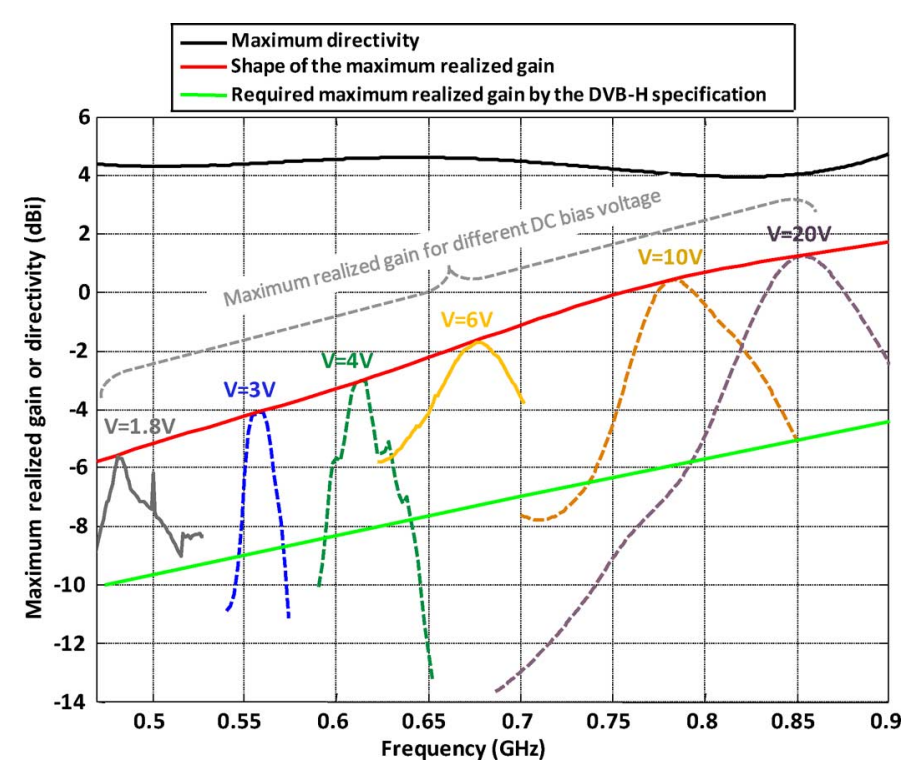

Fig. 25. Measured maximum realized gain and directivity according to the DC bias voltage.

TABLE II

Measured Total EfFiciencies AcCording to the DC Bias Voltages

\begin{tabular}{|c|c|c|c|c|c|c|}
\hline DC bias voltage & $\mathrm{V}=1.8 \mathrm{~V}$ & $\mathrm{~V}=3 \mathrm{~V}$ & $\mathrm{~V}=4 \mathrm{~V}$ & $\mathrm{~V}=6 \mathrm{~V}$ & $\mathrm{~V}=10 \mathrm{~V}$ & $\mathrm{~V}=20 \mathrm{~V}$ \\
\hline $\begin{array}{c}\text { Measured total } \\
\text { efficiencies }\end{array}$ & $10 \%$ & $14 \%$ & $17 \%$ & $20 \%$ & $27 \%$ & $32 \%$ \\
\hline
\end{tabular}

all over the whole DVB-H band. In the worst case, i.e., for a 2 V DC bias voltage, the antenna is matched with $\left|\mathrm{S}_{11}\right|<-6 \mathrm{~dB}$ in a bandwidth which is covering more than one channel of the DVB-H band at $-6 \mathrm{~dB}$.

Radiated performances of the final device (with the screen, the battery, the transceiver, etc.) are evaluated in an anechoic chamber. Maximum directivities, maximum realized gains and total efficiencies have been measured for six varactor diode DC polarizations and for the two antennas. Because of the structure symmetry, only antenna 1 performances are plotted (performances are quite similar for both antennas). Results are depicted in Fig. 25. It summarizes the measured maximum realized gains and plots their trend curve over the DVB-H band (red curve). This latter is finally compared with the one defined by the DVB-H application specifications (green curve). The maximum realized gain remains higher than the one required by the DVB-H specifications. The measured total efficiencies corresponding to the six values of the DC bias voltage are summarized in the Table II.

Table III exhibits both $\mathrm{E}_{\varphi}$ and $\mathrm{E}_{\theta}$ in the $\varphi=0^{\circ}(\mathrm{xOz})$ and $\varphi=90^{\circ}(\mathrm{yOz})$ planes for two DC bias voltages of the varactor diode and for the antenna 1

Both polarizations are high and equal in given directions. Thanks to this polarization diversity, antennas are able to receive all polarizations, which is a definite advantage considering the multipath of received signals.

However, the DVB-H specifications depend on the total radiated field $E_{\text {abs }}=\sqrt{E_{\theta}^{2}+E_{\varphi}^{2}}$, it is representing in Table IV for the antenna 1 in the $\mathrm{xOz}, \mathrm{yOz}$ and $\mathrm{xOy}$ planes. It should be noted that during the radiation pattern measurement for the first input, the second one was fitted with a $50 \Omega$ load and vice versa.
TABLE III

$\mathrm{E}_{\varphi}, \mathrm{E}_{\theta}$ AND $\mathrm{E}_{\mathrm{abs}}$ FOR Two Planes AND Two DC Bias Voltages

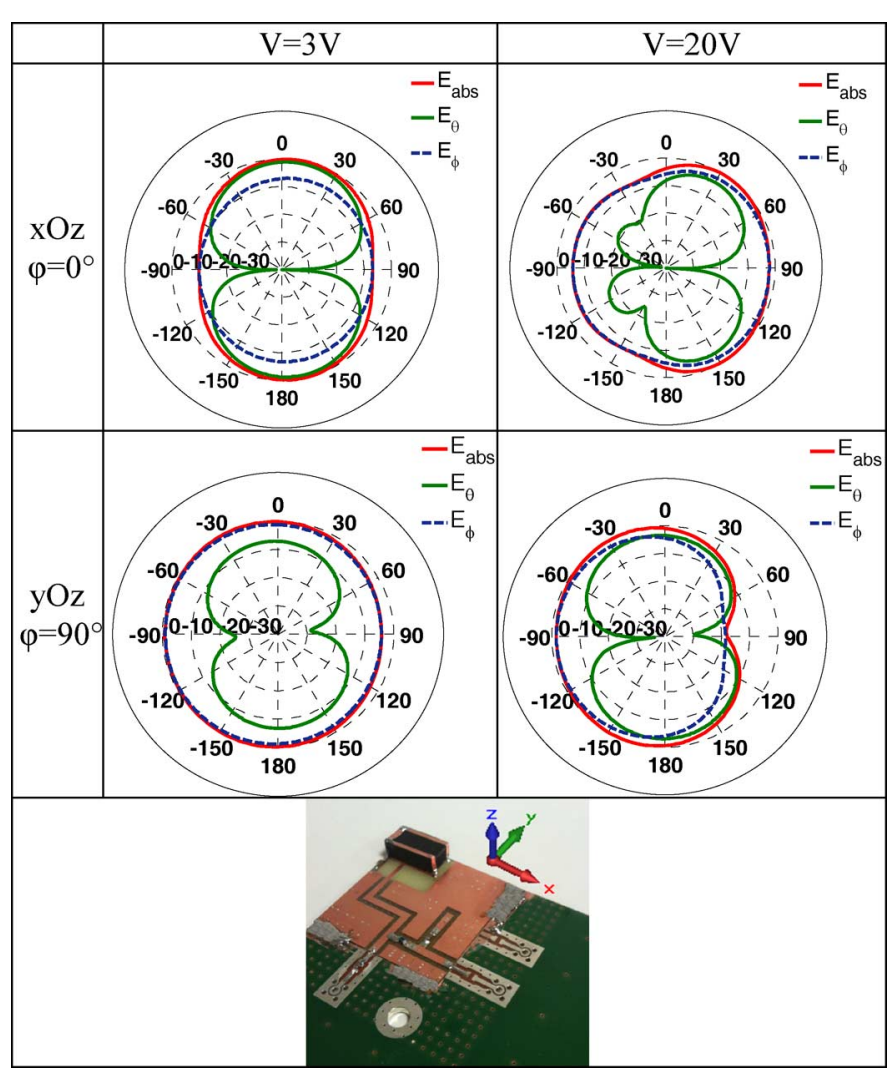

Measurement and simulation are in good agreement. Regarding now diversity operations, the simulated 3-D radiation patterns have been plotted on Fig. 26 for each antenna. The results clearly show that this device offers the possibility to perform both space and pattern diversity.

\section{B. Diversity Performances Measurement}

The performances of wireless communication systems can be greatly improved using antenna diversity techniques. The parameters usually presented to evaluate the diversity performances are the correlation coefficient [26], [27] and the effective diversity gain (EDG) [28]. The definition of the diversity gain and the measurement method in a mode-stirred reverberation chamber are presented in [29].

1) Envelope Correlation Coefficient: The correlation between the signals received by the two antennas can be evaluated through the envelope correlation coefficient. The latter can therefore be used to check whether the radiation pattern is actually reconfigured. In an anisotropic channel, the envelope correlation coefficient can be determined using the farfields [see (2)] or the S parameters [see (3)]. Its value varies between 0 and 1 , with a higher value corresponding to more similar signals. The necessary condition for diversity is an envelope correlation coefficient lower than 0.5 [28]

$$
\rho_{e}=\frac{\left|\iint\left(E_{\theta 1} E_{\theta 2}^{*}+E_{\varphi 1} E_{\varphi 2}^{*}\right) d \Omega\right|^{2}}{\iint\left(E_{\theta 1} E_{\theta 1}^{*}+E_{\varphi 1} E_{\varphi 1}^{*}\right) d \Omega \cdot \iint\left(E_{\theta 2} E_{\theta 2}^{*}+E_{\varphi 2} E_{\varphi 2}^{*}\right) d \Omega}
$$


TABLE IV

Measured (Blue Line) and Simulated (Red Line) Radiation Patterns FOR TWO DC BIAS VOLTAGES

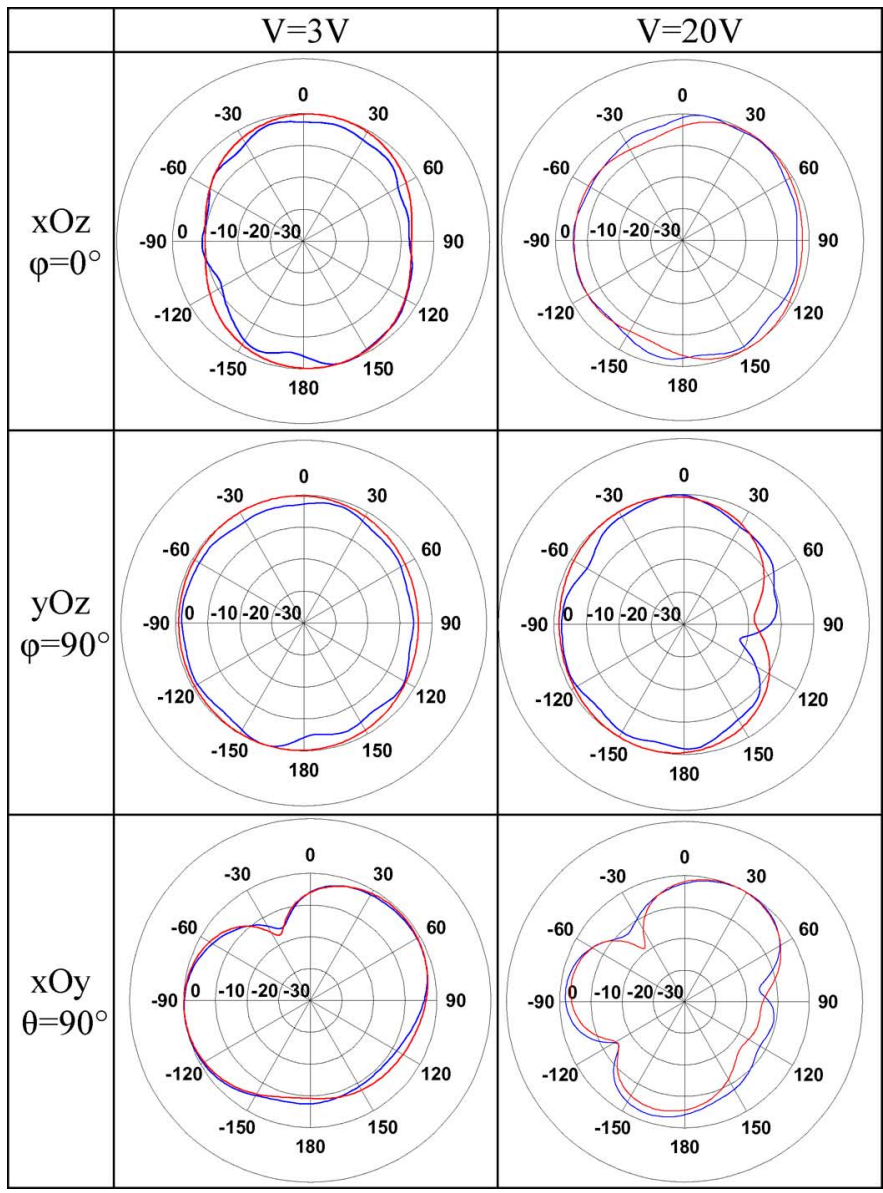

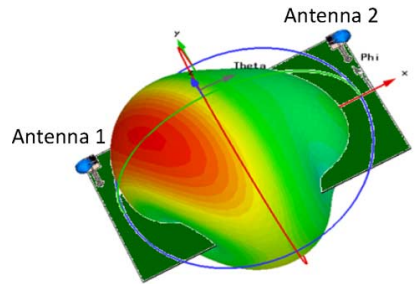

(a)
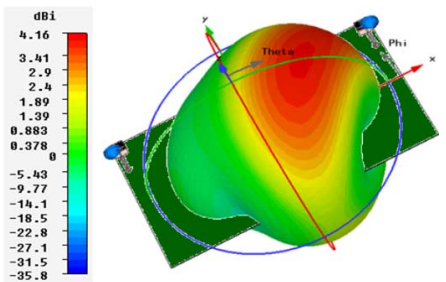

(b)
Fig. 26. Directivity patterns when the antenna 2 (a) or the antenna 1 (b) is excited.

$\rho_{e}=\frac{\left|S_{11}^{*} S_{12}+S_{21}^{*} S_{22}\right|^{2}}{\left(1-\left(\left|S_{11}\right|^{2}+\left|S_{21}\right|^{2}\right)\right)\left(1-\left(\left|S_{22}\right|^{2}+\left|S_{12}\right|^{2}\right)\right)}$.

Fig. 27 shows the envelope correlation coefficient calculated with the (3) for a $10 \mathrm{~V}$ polarization of the varactor diode. It remains lower than 0.5 (equals to $6 \cdot 10^{-3}$ ), that allows to conclude that the radiation patterns is reconfigured on the working band at $10 \mathrm{~V}$. The same phenomenon can be observed for other values of DC bias voltage.

2) Effective Diversity Gain: The effective diversity gain is evaluated in a mode-stirred reverberation chamber. The schematic of the measurement process is shown in Fig. 28. A reverberation chamber is a metallic cavity which supports a large number of resonant cavity modes. The statistically

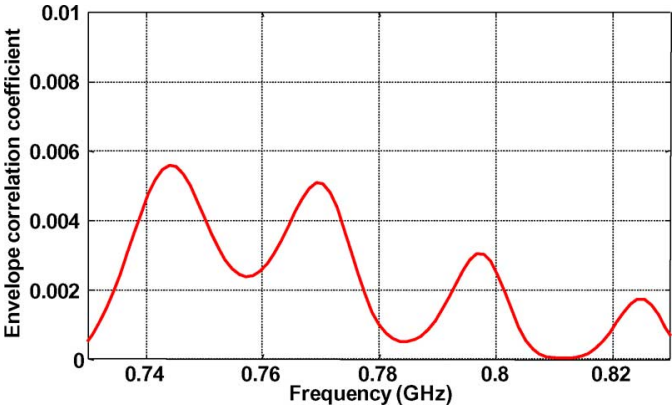

Fig. 27. Envelope correlation coefficient for a $10 \mathrm{~V}-\mathrm{DC}$ bias voltage.

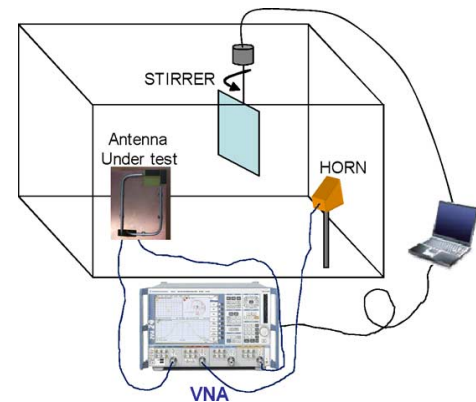

Fig. 28. Measurement process in the mode stirred reverberation chamber.

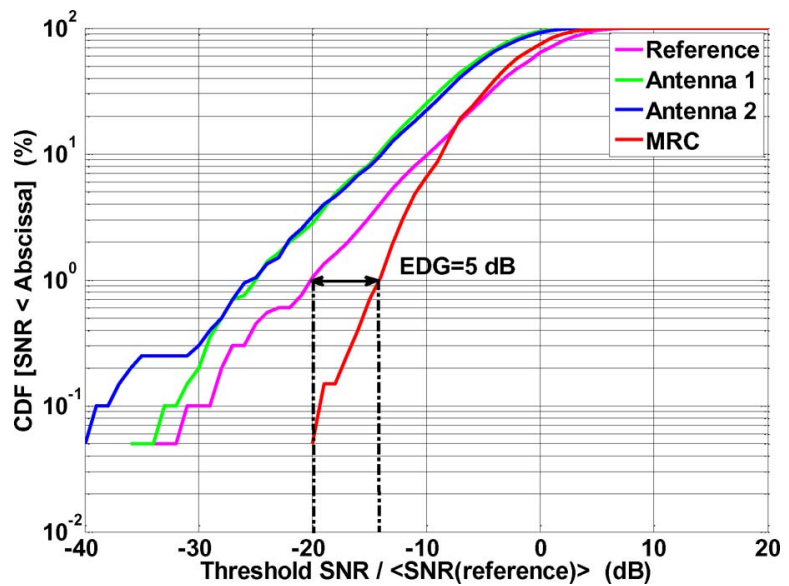

Fig. 29. Effective diversity gain for a $10 \mathrm{~V}-\mathrm{DC}$ bias voltage.

uniform field distribution can be obtained by mechanically steering these modes inside the chamber [30]-[32].

As shown in Fig. 28, a fixed horn antenna excites the chamber where the antenna under test is positioned on a rotating arm. To obtain a statistically uniform channel, the stirrer and the antenna under test are rotated around the $\mathrm{z}$ axis.

The cumulative probability density (CDF) is calculated from the signal-to-noise ratio (SNR) measurements. An example of the CDF curve computed at $780 \mathrm{MHz}$ is plotted in Fig. 29. In abscissa, the threshold SNR is normalized by the SNR of the reference antenna. A half-wavelength dipole antenna, also measured in the reverberation chamber, has been used to provide this reference. This one has been used in order to evaluate the effective diversity gain. It was matched at the measured frequency where it presented a total efficiency near $100 \%$. 
It is obvious that the diversity techniques enhance the reception quality, while the effective diversity gain at a $1 \%$ probability is higher than $0 \mathrm{~dB}$. At $780 \mathrm{MHz}$, i.e., for a varactor diode polarization equals to $10 \mathrm{~V}$, it is equal to $5 \mathrm{~dB}$ for Maximum Ratio Combining (MRC). Because antennas efficiencies are lower at the beginning of the DVB-H band, the effective diversity gain at a $1 \%$ is lower and equals $3.5 \mathrm{~dB}$ at $470 \mathrm{MHz}$.

\section{CONCLUSION}

The paper started by underlining the interest of using a magneto-dielectric material in the case of a 3D Inverted F Antenna application. To ensure the relevance and usefulness of this investigation, the use of such a material has been compared with the equivalent dielectric case for lossless materials. Indeed, losses enhance the input impedance bandwidth and to carefully compare and show the relevance of using a magneto-dielectric material rather than a dielectric one, the best way is to consider lossless materials. Thus, while disregarding losses, results exhibit that using a magneto-dielectric material allows enhancing the impedance bandwidth. Of course, considering the real case, i.e., manufactured magneto-dielectric material with losses, the impedance bandwidth is all the more enhanced. To finish about the magneto-dielectric material study, simulations in an antenna application have been corroborated by the realization and the measurement of a prototype.

To cover the ultra-wide DVB-H band, the second axe of the paper proposed the integration of a varactor diode. Integrate such an active component for antenna application requires some attention. First of all, its position and the capacitance range have been determined to continuously cover the DVB-H band. A varactor diode corresponding to the requirements has been found but its characteristics (given by its datasheet) were not accurate enough for RF frequency bands and do not give enough information for antenna application point of view. The novelty in this paper is the characterization of the varactor diode. Its electromagnetic model has been determined and integrated in the simulator. This characterization has highlighted that this linear model is only available for low injected powers, till $-5 \mathrm{dBm}$. In our case, i.e., for reception devices, the injected power to the diode is far lower than $-5 \mathrm{dBm}$. It is thus important to notice that the proposed antenna design is not available for devices working in transmission.

Finally, the final design, which takes into account both the magneto-dielectric material and the characterized varactor diode, has been integrated in the tablet dedicated to the DVB-H reception. Material dimensions are $11 \mathrm{~mm} \times 7 \mathrm{~mm} \times 3.5 \mathrm{~mm}$, i.e., $\lambda_{0} / 49 \times \lambda_{0} / 91 \times \lambda_{0} / 160$ at $470 \mathrm{MHz}$ and the dedicated area for the antenna structure is about $13.5 \mathrm{~mm} \times 12 \mathrm{~mm} \times 4.3$ $\mathrm{mm}$, i.e., $\lambda_{0} / 47 \times \lambda_{0} / 53 \times \lambda_{0} / 148$ at $470 \mathrm{MHz}$.

The device was measured both in anechoic and reverberation chambers. The anechoic chamber measurements show good performances. The realized gain remains higher than the one required by the DVB-H application and the total efficiency higher than $10 \%, 32 \%$ is obtained for the highest DVB-H frequency band. The reverberation measurement shows a $5 \mathrm{~dB}$ effective diversity gain at $780 \mathrm{MHz}$ for maximum ratio combining (MRC). The space diversity has allowed enhancing the quality and reliability of the wireless link.

\section{REFERENCES}

[1] R. C. Hansen, "Fundamental limitations in antennas," Proc. IEEE, vol. 69, no. 2, pp. 170-182, Feb. 1981.

[2] J. S. McLean, "A re-examination of the fundamental limits on the radiation Q of electrically small antennas," IEEE Trans. Antennas Propag., vol. 44, no. 5, p. 672, May 1996.

[3] R. Collin and S. Rothschild, "Evaluation of antenna Q," IEEE Trans. Antennas Propag., vol. AP-12, no. 1, pp. 23-27, Jan. 1964.

[4] A. K. Skrivervik, J.-F. Zurcher, O. Staub, and J. R. Mosig, "PCS antenna design: The challenge of miniaturization," IEEE Antennas Propag. Mag., vol. 43, no. 4, pp. 12-27, Aug. 2001.

[5] R. Caso, A. D'Alessandro, A. A. Serra, P. Nepa, and G. Manara, "A compact dual-band PIFA for DVB-T and WLAN applications," IEEE Trans. Antennas Propag., vol. 60, no. 4, pp. 2084-2087, Apr. 2012.

[6] Y. Cheon, J. Lee, and J. Lee, "Quad-band monopole antenna including LTE $700 \mathrm{MHz}$ with magneto-dielectric material," IEEE Antennas Wireless Propag. Lett., vol. 11, pp. 137-140, 2012.

[7] L. Huitema, M. Koubeissi, C. Decroze, and T. Monediere, "Ultrawideband dielectric resonator antenna for DVB-H and GSM applications," IEEE Antennas Wireless Propag. Lett., vol. 8, pp. 1021-1027, 2009.

[8] M. Berg, M. Komulainen, V. Palukuru, H. Jantunen, and E. Salonen, "Frequency-tunable DVB-H antenna for mobile terminals," in Proc. IEEE Int. Symp. Antennas Propag. Soc., Jun. 9-15, 2007, pp. $1072-1075$.

[9] L. Huang and P. Russer, "Electrically tunable antenna design procedure for mobile applications," IEEE Trans. Microw. Theory Tech., vol. 56, no. 12, pp. 2789-2797, Dec. 2008.

[10] D.-H. Choi, Y.-T. Im, Y.-J. Cho, and S.-O. Park, "A tunable antenna for DVB-H applications," IEEE Antennas Wireless Propag. Lett., vol. 6, pp. 515-517, 2007.

[11] Y. Li, Z. Zhang, W. Chen, Z. Feng, and M. F. Iskander, "A compact DVB-H antenna with varactor-tuned matching circuit," Microw. Opt. Technol. Lett., vol. 52, pp. 1786-1789, 2010.

[12] Digital Video Broadcasting (DVB), DVB-H Implementation Guidelines, ETSI TR $102377 \mathrm{v} 1.2 .1$, Nov. 2005, ETSI TR 102377 v1.2.1.

[13] H. Mosallaei and K. Sarabandi, "Magneto-dielectrics in electromagnetics: Concept and applications," IEEE Trans. Antennas Propag., vol. 52 , no. 6, pp. $1558-1567$, Jun. 2004.

[14] P. M. T. Ikonen, K. N. Rozanov, A. V. Osipov, P. Alitalo, and S. A. Tretyakov, "Magnetodielectric substrates in antenna miniaturization: Potential and limitations," IEEE Trans. Antennas Propag., vol. 54, no. 11, pp. 3391-3399, Nov. 2006.

[15] P. M. T. Ikonen, K. N. Rozanov, A. V. Osipov, P. Alitalo, and S. A. Tretyakov, "Magnetodielectric substrates in antenna miniaturization: Potential and limitations," IEEE Trans. Antennas Propag., vol. 54, no. 11, pp. 3391-3399, Nov. 2006.

[16] R. C. Hansen and M. Burke, "Antennas with magneto-dielectrics," Microw. Opt. Technol. Lett., vol. 26, pp. 75-78, Jul. 2000.

[17] C. Niamien, S. Collardey, A. Sharaiha, and K. Mahdjoubi, "Compact expressions for efficiency and bandwidth of patch antennas over lossy magneto-dielectric materials," IEEE Antennas Wireless Propag. Lett., vol. 10, pp. 63-66, 2011.

[18] F. Ferrero, A. Chevalier, J. M. Ribero, R. Staraj, J. L. Mattei, and Y. Queffelec, "A new magneto-dielectric material loaded, tunable UHF antenna for handheld devices," IEEE Antennas Wireless Propag. Lett., vol. 10, pp. 951-954, 2011.

[19] J. F. Pintos, A. Louzir, P. Minard, J. Perraudeau, J. L. Mattei, D. Souriou, and P. Queffelec, "Ultra-miniature UHF antenna using magneto-dielectric material," in Proc. 14th Int. Symp. Antenna Technol. Appl. Electromagn. Amer. Electromagn. Conf. (ANTEM-AMEREM), Jul. 5-8, 2010, pp. 1-4.

[20] J.-L. Mattei, L. Huitema, P. Queffelec, J.-F. Pintos, P. Minard, A. Sharahia, B. Jamnier, F. Ferrero, R. Staraj, D. Souriou, and A. Thakur, "Suitability of Ni-Zn ferrites ceramics with controlled porosity as granular substrates for mobile handset miniaturized antennas," IEEE Trans. Magn., vol. 47, no. 10, pp. 3720-3723, Oct. 2011.

[21] Weir and B. William, "Automatic measurement of complex dielectric constant and permeability at microwave frequencies," Proc. IEEE, vol. 62, no. 1, p. 33,36, Jan. 1974

[22] L. Huitema, M. Koubeissi, C. Decroze, and T. Monediere, "Overview of two ultra compact antennas using original materials with pattern diversity," in Proc. Int. Workshop Antenna Technol. (iWAT), Mar. 7-9, 2011, pp. 50-53.

[23] L. Huitema, M. Hajj, T. Monédière, D. Souriou, A. Chevalier, J.-L. Mattei, and P. Queffelec, "Overview of reconfigurable and compact antennas using a magneto-dielectric material," in Progress Electromagn. Res. Symp., Marrakesh, Morocco, Mar. 20-23, 2011.

[24] Aeroflex Metelics Datasheet, [Online]. Available: http://www.aeroflex. com/AMS/Metelics/pdfiles/MGV_Series_Hyperabrupt_A17041.pdf 
[25] L. Huitema, T. Reveyrand, E. Arnaud, C. Decroze, and T. Monediere, "A compact and reconfigurable DVB-H antenna for mobile handheld devices," in Proc. 5th Eur. Conf. Antennas Propag. (EUCAP), , Apr. 11-15, 2011, pp. 1314-1317.

[26] G. A. Mavridis, J. N. Sahalos, and M. T. Chryssomalis, "Spatial diversity two branch for wireless devices," IEEE Lett., vol. 42, pp. 266-268, 2006.

[27] M. B. Knudsen and G. F. Pedersen, "Spherical outdoor to indoor power spectrum model at the mobile terminal," IEEE J. Select. Areas Commun., vol. 20, no. 6, pp. 1156-1169, Aug. 2002.

[28] S. Blanch, J. Romeu, and I. Corbella, "Exact representation of antenna system diversity performance from input parameter description," Electron. Lett., vol. 39, no. 9, pp. 705-707, May 2003.

[29] P. S. Kildal, K. Rosengren, J. Byun, and J. Lee, "Definition of effective diversity gain and how measure it in a reverberation chamber," Microw. Opt. Technol. Lett., vol. 34, pp. 56-59, 2002.

[30] R. G. Vaughan and J. B. Andersen, "Antenna diversity in mobile communications," IEEE Trans. Veh. Technol., vol. 36, no. 4, pp. 149-172, Nov. 1987.

[31] T. Bolin, A. Derneryd, G. Kristensson, V. Plicanic, and Z. Ying, "Twoantenna receive diversity performance in indoor environment," Electron. Lett., vol. 41, no. 22, pp. 1205-1206, Oct. 2005.

[32] M. Mouhamadou, C. A. Tounou, C. Decroze, D. Carsenat, and Monediere, "Active measurements of antenna diversity performances using a specific test-bed, in several environments," Int. J. RF Microw. Comput.-Aided Eng., pp. 264-271, May 2010.

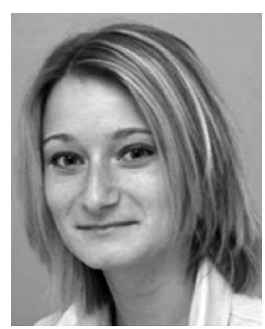

Laure Huitema was born in Limoges, France, in 1984. She received the M.S. and Ph.D. degrees in telecommunications high frequencies and optics from Limoges University, Limoges, France, in 2008 and 2011, respectively.

From 2011 to 2012, she was a Postdoctoral Research Fellow at the Atomic Energy Commission (CEA), Laboratory of Electronics and Information Technology (LETI), Grenoble, France. She is currently an Associate Professor in the OSA (Wireless communications and Effect of EM Wave) Department of XLIM Research Institute. Her research interests include active antennas, Dielectric Resonator Antennas and also multiband antennas.

Dr. Huitema is the recipient of the best student paper award at the 2010 IEEE International Workshop on Antenna Technology (iWAT 2010) and of the best student paper award at the 2010 Journées de Charactérisation Microondes et Matériaux (JCMM 2010).

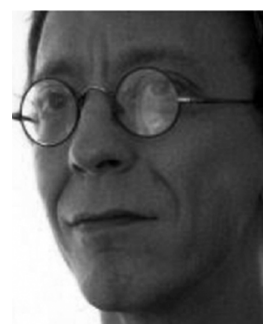

Tibault Reveyrand (M'07) received the Ph.D degree from the University of Limoges, Limoges, France, in 2002.

From 2002 to 2004, he was a Postdoctoral Scientist with CNES (French Space Agency). From 2005 to 2013, he was a CNRS Engineer at XLIM. In 2013, he joined University of Colorado at Boulder, Boulder, CO, USA, as a Research Associate. His research interests include the characterization and modeling of RF and microwave nonlinear components and devices.

Dr. Reveyrand was the recipient of the 2002 European GaAs Best Paper Award and is a member of the IEEE MTT-11 "Microwave Measurements" Technical Committee.

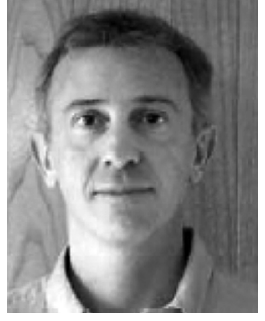

Jean-Luc Mattei received was born in France, in 1961. He received the Ph.D. degree in solid state physics from University Joseph Fourier, Grenoble, France, in 1990.

$\mathrm{He}$ is currently an Assistant Professor in the Electronic Department of the University of Brest and Member of the Lab-STICC (UMR CNRS 6285). His main research activities include the ferrite processing (powder preparation and sintering), the study of heterogeneous granulars materials for applications in the microwave range, and mainly about the demagnetizing effects. He is also interested in the modeling of electromagnetic fields in composite media.

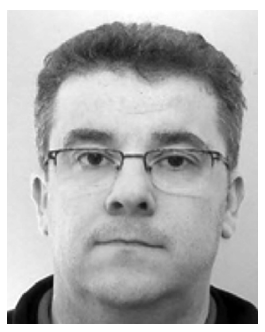

Eric Arnaud was born in France, in 1970. He received the Diplôme D'Etudes Supérieures Specialisées (DESS) and Ph.D degrees in electronic and telecommunication from the University of Limoges, Limoges, France, in 1994 and 2010, respectively. He did his Ph.D. on circularly polarized EBG antenna.

From 1996 to 2001, he has been Microwave responsible of Free-Electron Laser (L.U.R.E laboratory). Since 2001, he has been in charge of XLIM laboratory antenna test range and he participated to several research projects related to design, development and characterization of antennas. His research interests include the fields of circularly polarized EBG antenna and realization of antennas through ink-jetting of conductive inks on RF substrates

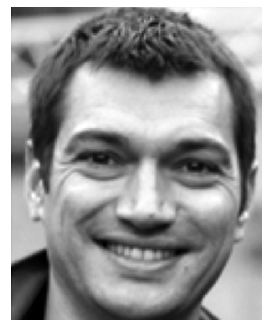

Cyril Decroze received the Ph.D. degree in telecommunications engineering from the University of Limoges, Limoges, France, in 2002.

$\mathrm{He}$ is currently an Associate Professor with the Wave and Associated Systems (OSA) Department, XLIM Research Institute, University of Limoges. Since 2006, he has been in charge of the wireless systems activity in the XLIM-OSA Department His research interests include antennas design, propagation channel, MIMO systems, and digital wireless communications.

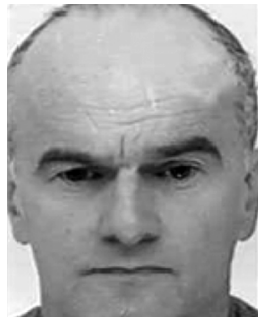

Thierry Monediere was born in 1964, in Tulle, France. He received the Ph.D. degree from the IRCOM Laboratory, University of Limoges, Limoges, France, in 1990.

$\mathrm{He}$ is currently a Professor at the University of Limoges and develops his research activities in Xlim Laboratory (UMR CNRS/University of Limoges). He research interests include multifunctions antennas, EBG antennas, and active antennas. 